\title{
Modeling the Influence of Surface Free Energy on Moisture Damage of Recycled Asphalt Concrete
}

\author{
Saad Issa Sarsam ${ }^{1}$, Rana Khalid Hamdan² \\ ${ }^{I}$ Department of Civil Engineering, University of Baghdad, Baghdad-Iraq \\ ${ }^{2}$ MSc student, Department of Civil Engineering, University of Baghdad, Baghdad-Iraq \\ saadisasarsam@coeng.uobaghdad.edu.iq
}

\begin{abstract}
Recycling is a sustainable process for restoration of the pavement quality. In this investigation, aged binder was recycled by digestion with $(0.5,1.0$, and 1.5$) \%$ of polyethylene and crumb rubber. The recycled binder was implemented in the preparation of Marshal specimens. The surface free energy of the control and recycled binder was determined using the Sessile drop method. Specimens were tested under repeated indirect tensile and double punching shear stresses with the aid of pneumatic repeated load system (PRLS). Another group of specimens was tested for moisture damage, then subjected to the same loading sequence. Specimens were subjected to 1200 load repetitions under stress level of $0.138 \mathrm{MPa}$ at $25{ }^{\circ} \mathrm{C}$. The load was sustained for 0.1 second followed by 0.9 seconds of rest period. The permanent deformation was measured before and after moisture damage process for each testing technique. Regression analysis is used to develop a model for the influence of surface free energy on the deformation and the moisture damage using the SPSS Software. It was concluded that the obtained model can explain $82 \%$ of the variation in moisture damage due to the influence of surface free energy.
\end{abstract}

Keywords: recycling; asphalt concrete; repeated shear and tensile stress; moisture damage; surface free energy

\section{Introduction}

Authors all around the world have provided models to predict pavement performance both on local and on global level. Several models predicting the pavement performance have been analyzed, and it has been determined that the best predicting models are the ones formed using databases for the territory where they are intended to predict pavement properties, Matic et al, (2016). Expression and mathematical models have been obtained for the determination of cyclic tensile strength of the asphalt concrete, which considers the damage accumulation and the history of loading. Comparison of the calculation results performed under the obtained expression, and experimental tests showed that the obtained expression describes satisfactorily the cyclic tensile strength of the asphalt concrete. It was concluded that the obtained expression for determination of the cyclic tensile strength for the asphalt concrete can be used for the prediction of fatigue strength of the asphalt concrete pavement, Iskakbayev et al, (2017).

A multi-objective nonlinear optimization model was established by Zhou and Chen, (2019) according to the residual sum of squares of storage modulus and loss modulus from dynamic modulus test. The results of statistical analysis indicated that the fitting curves of fractional models with fewer mechanical elements and fitting parameters were much smoother in comparison with the traditional integer model with many unknown parameters. A new nonlinear second order hyper-elastic-visco-plastic-damage constitutive model in multi dimensions was developed by Panoskaltsis and Panneerselvam, (2007) and its theoretical foundations are presented. It was concluded that the model is used to analyze experiments for asphalt concrete both in the elastic as well as in the irreversible domain of the material. Model's comparisons to experiments are very favorable. The experiments are analyzed both as homogeneous and as boundary-value problems. Sarsam and Al-Azawi, (2013) concluded that the stripping potential as indicated by the index of retained strength, is highly dependent on the 
stiffness of asphalt concrete. On the other hand, experience and previous recycling processes made by many agencies, have indicated that the recycling of asphalt pavements is a very beneficial approach from technical, economic and environmental perspectives, Ramanujam, (2000); Perez et al., (2004). Recycling is a sustainable solution for reserving the resources and protecting the environment, Nurmaidah and Pradana, (2019). Silva et al., (2012) addressed that, using rejuvenator can improves the performance of the totally recycled HMA mixtures (i.e., longer life cycle), and reduces the mixing temperature (i.e., lower energy consumption).

It was concluded that totally recycled HMAs can be a good alternative for road paving. Asphalt pavement performance is related to cohesive and adhesive bonding within the asphaltaggregate system, and the cohesive and adhesive bonding are related to the surface free energy characteristics of the system. The percentage of the surface area of aggregate that has been exposed to water can be calculated using the surface free energy concept after performing the controlled-stress test and can be used as a significant index to quantify the level of adhesive fracture Kim et al, (2003). Pradyumna and Jain, (2016) describes the comparison of properties of mixture with recycling agents, which has been prepared in laboratory on the RAP material, and their performance has been compared with virgin mixes. It was concluded that the laboratory results indicate that the bituminous mixes with RAP and recycling agent provide better performance compared to virgin mixes. Sarsam, (2007) investigated the recycling of asphalt concrete. It was concluded that Recycling has a positive effect on Asphalt concrete overall properties. The influence of surface free energy on the properties of asphalt cement and how it is altered due to the addition of modifiers was investigated by Sarsam and Abdulhussain, (2018). It was concluded that Carbon black is more appropriate additive, it gives an ultimate total surface free energy increment of $7.7 \%$ and $6 \%$ as compared with $2.8 \%$ and $3.1 \%$ for sulfur when Wilhelmy plate and Sessile drop methods have been implemented respectively.

The aim of this investigation is to model the influence of surface free energy on moisture damage of recycled asphalt concrete.

\section{Materials and Methods}

\subsection{Asphalt Cement}

Asphalt cement of 40-50 penetration grade was obtained from Dora refinery; the physical properties are listed in Table 1.

Table1. Physical Properties of Asphalt Cement

\begin{tabular}{|c|c|c|c|}
\hline Test procedure as per ASTM, (2013) & Result & Unit & $\begin{array}{c}\text { SCRB Specification, } \\
\text { (2003) }\end{array}$ \\
\hline Penetration $\left(25^{\circ} \mathrm{C}, 100 \mathrm{~g}, 5 \mathrm{sec}\right)$ ASTM D 5 & 40 & $1 / 10 \mathrm{~mm}$ & $40-50$ \\
\hline Ductility $\left(25^{\circ} \mathrm{C}, 5 \mathrm{~cm} / \mathrm{min}\right)$. ASTM D 113 & 167 & $\mathrm{Cm}$ & $\geq 100$ \\
\hline Softening point (ring \& ball). ASTM D 36 & 50 & ${ }^{\circ} \mathrm{C}$ & $50-60$ \\
\hline Specific gravity at $25^{\circ} \mathrm{C}$, ASTM D 70 - 03 & 1.04 & - & - \\
\hline \multicolumn{4}{|c|}{ After Thin-Film Oven Test ASTM D-1754 } \\
\hline $\begin{array}{c}\text { Retained penetration of original, \%, ASTM } \\
\text { D 946 }\end{array}$ & 87 & $1 / 10 \mathrm{~mm}$ & $>55$ \\
\hline $\begin{array}{c}\text { Ductility at } 25^{\circ} \mathrm{C}, 5 \mathrm{~cm} / \mathrm{min},(\mathrm{cm}) \text { ASTM D- } \\
113\end{array}$ & 117 & $\mathrm{Cm}$ & $>25$ \\
\hline $\begin{array}{c}\text { Loss in weight }\left(163^{\circ} \mathrm{C}, 50 \mathrm{~g}, 5 \mathrm{~h}\right) \% \text { ASTM D- } \\
1754\end{array}$ & 0.32 & $\%$ & - \\
\hline
\end{tabular}

\subsection{Crumb rubber}

It was produced by mechanical shredding and was obtained from tires factory at AL- 
Najaf governorate, the rubber type is (recycled) from used tires. Table 2 show the grain sizes distribution of crumb rubber.

Table 2. Gradation of crumb rubber

\begin{tabular}{|l|c|c|}
\hline Sieve No. & Sieve Size(mm) & Passing by weight \% \\
\hline No.16 & 1.18 & 100 \\
\hline No. 30 & 0.9 & 78 \\
\hline No. 50 & 0.3 & 25 \\
\hline No. 200 & 0.075 & 0 \\
\hline
\end{tabular}

\subsection{Polyethylene}

It was a Low-Density Polymers, found to be suitable for blending with asphalt with a melting temperature not more than $180^{\circ} \mathrm{C}$. Table 3 show the mechanical and thermal Properties of Polyethylene.

Table 3. Mechanical and Thermal Properties of Low-Density Polyethylene

\begin{tabular}{|l|l|l|}
\hline Properties & Unit & Value \\
\hline Tensile strength & $\mathrm{MPa}$ & 10 \\
\hline Tensile Elongation & $\%$ & $>350$ \\
\hline Flexural Modulus & $\mathrm{MPa}$ & 8 \\
\hline Hardness (Shore D) & $\ldots \ldots . . .$. & 50 \\
\hline Vicat Softening point & ${ }^{\circ} \mathrm{C}$ & 88 \\
\hline Brittleness Temperature & ${ }^{\circ} \mathrm{C}$ & $<-175$ \\
\hline
\end{tabular}

\subsection{Coarse and Fine Aggregate}

The aggregate used in this work was obtained from the Nahrawan quarry. Crushed Sand was used as fine aggregate (particle size passing sieve No.4 and retained on sieve No.200). The sizes of coarse aggregate range between $12.5 \mathrm{~mm}$ to $4.75 \mathrm{~mm}$ according to SCRB, (2003) specification. Table 4 shows the physical properties of aggregate.

Table 4. Physical Properties of Coarse and Fine Aggregate

\begin{tabular}{|c|c|c|}
\hline Property & Value & $\begin{array}{c}\text { ASTM, (2013) } \\
\text { Designation No. }\end{array}$ \\
\hline \multicolumn{3}{|c|}{ Coarse Aggregate } \\
\hline Bulk specific gravity & 2.639 & C127-01 \\
\hline Apparent specific gravity & 2.614 & C127-01 \\
\hline Water absorption \% & 1.3 & C127-01 \\
\hline Wear \% (los Angeles abrasion) & 13.05 & C131-03 \\
\hline \multicolumn{3}{|c|}{ Fine aggregate } \\
\hline Bulk specific gravity & 2.727 & C128-01 \\
\hline Apparent specific gravity & 2.750 & C128-01 \\
\hline Water absorption \% & 2.3 & C128-01 \\
\hline
\end{tabular}

\subsection{Selection of Aggregate Gradation}

The selected gradation is that used for Wearing Course with $12.5(\mathrm{~mm})$ nominal maximum size according to specification of SCRB, (2003). Table 5 shows the selected aggregate gradation. 
Table 5. Specification Limits and Gradation of HMA Mixtures for Wearing Course

\begin{tabular}{|c|c|c|c|}
\hline \multirow{2}{*}{$\begin{array}{l}\text { Sieve } \\
\text { Opening } \\
(\mathrm{mm})\end{array}$} & \multirow{2}{*}{$\begin{array}{l}\text { Sieve } \\
\text { Size }\end{array}$} & \multicolumn{2}{|c|}{ \% passing by weight of total aggregate } \\
\hline & & $\begin{array}{l}\text { Selected } \\
\text { gradation }\end{array}$ & $\begin{array}{l}\text { SCRB, (2003) specifications Limit } \\
\text { For Wearing course (Type IIIB) }\end{array}$ \\
\hline 12.5 & $1 / 2 "$ & 100 & 100 \\
\hline 9.5 & $3 / 8^{\prime \prime}$ & 95 & $90-100$ \\
\hline 4.75 & No.4 & 70 & $55-85$ \\
\hline 2.36 & No.8 & 49.5 & $32-67$ \\
\hline 0.3 & No.50 & 15 & $7-23$ \\
\hline 0.075 & No.200 & 7 & $4-10$ \\
\hline
\end{tabular}

\subsection{Mineral Filler}

In this study, one type of mineral filler Limestone dust has been implemented. It was obtained from Al- Nahrawan factory. It is thoroughly dry and free from lumps or aggregations or fine particles, the physical properties are presented in table 6 .

Table 6. Physical Properties of Limestone Dust

\begin{tabular}{|l|l|}
\hline Property & Limestone Dust \\
\hline$\%$ passing sieve 200 & 96 \\
\hline Specific gravity & 2.68 \\
\hline
\end{tabular}

\subsection{Aging of Asphalt Cement}

To simulate the aging process of asphalt cement during its service life in the field, Asphalt cement was subjected to aging process using the thin film oven test apparatus, asphalt cement practices $163^{\circ} \mathrm{C}$ of heating for five hours in the rotating shelf of the oven. Asphalt cement was collected after the heating and cooled to room temperature. It was denoted as aged asphalt cement.

\subsection{Determination of Surface Free Energy of the Control and Recycled Binder}

The surface free energy is required to measure work of adhesion between aggregate and asphalt binder. These quantities are related to moisture sensitivity and adhesive fracture properties of the asphalt binder. The three components of which the surface free energy is composed for asphalt binder are the Lifshitz-van der Waals component, the Lewis base component and the Lewis acid component, Sarsam and Al Azzawi, (2013). The test sample was prepared by heating the binder to mixing temperature, a small quantity of asphalt binder was poured on the substrate. The quantity of asphalt poured forms an area of approximately $(5 \times 5) \mathrm{cm}$ in size, then left to cool for $24 \mathrm{~h}$ at room temperature. By using micro syringe, a probe liquid was dispensed over the prementioned smooth horizontal surface coated with asphalt from the top of the sample position, the tip of the micro syringe needle was approximately 5 $\mathrm{mm}$ away, By using a digital camera, the image of the drop of the liquid formed over the surface of the binder was captured and by analyzing the image using (Comef 4.4) software, contact angles were obtained. With the aid of work of adhesion theory and mathematical models, the three surface energy components of the asphalt binder were determined. Three probe liquids were used to measure the contact angle (distilled water, glycerol, Formamid). The surface free energy component of asphalt binder was determined by measuring its contact angles with various probe liquids for at least three replicates with each probe liquid. The surface free energy was calculated using the mathematical models presented by Little and Bhasin, (2006). Details of the testing and test results were published elsewhere, Sarsam and Hamdan, (2019). 


\subsection{Recycling of Aged Asphalt Cement}

\section{a. Preparation of recycled Asphalt Cement (Blended with Low-Density Polyethylene)}

The aged asphalt cement was recycled by digestion with polyethylene, asphalt cement was heated to $150{ }^{\circ} \mathrm{C}$ and then blended with Low-Density Polyethylene with different percentages of $(0.5,1$ and $1.5 \%$ by weight of asphalt cement) using mechanical mixer, it was prepared in the laboratory at a blending speed of about $200 \mathrm{rpm}$ and temperature of $160^{\circ} \mathrm{C}$ for 60 minutes to promote the physical and chemical bonding of the components.

\section{b. Preparation of recycled Asphalt Cement (Blended with Crumb Rubber)}

The aged asphalt cement was recycled by digestion with crumb rubber using the wet process. The asphalt cement was heated to $150{ }^{\circ} \mathrm{C}$ and then blended with crumb rubber with different percentages of $(0.5,1$ and $1.5 \%$ by weight of asphalt cement) at a blending speed of about $1500 \mathrm{rpm}$ for 60 minutes in the laboratory using mechanical mixer to promote the physical and chemical bonding of the components. During the blending process, the crumb rubber dispersed and reacts with the asphalt. Swelling and formation of bubbles could be observed after the blending process.

\section{c. Preparation of Asphalt Concrete Specimens}

The coarse and fine aggregates were combined with mineral filler to meet the specified gradation of wearing course. The combined aggregate mixture was heated to a temperature of $150{ }^{\circ} \mathrm{C}$ before mixing with asphalt cement. The asphalt cement or the treated asphalt cement with polyethylene and crumb rubber was heated to the same temperature of $150{ }^{\circ} \mathrm{C}$, then it was added to the heated aggregate to achieve the desired amount and mixed thoroughly using mechanical mixer for two minutes until all aggregate particles were coated with thin film of asphalt cement. Marshall Size specimens were prepared in accordance with ASTM D1559, (2013). The optimum asphalt content was determined as per the procedure above to be 5.3\% by weight of aggregates. The prepared Marshall Size Specimens were divided into three sets, the first set was subjected to the repeated indirect tensile stress at $25^{\circ} \mathrm{C}$, while the second set was subjected to repeated double punching shear stress at $25^{\circ} \mathrm{C}$. The permanent deformation was determined after 1200 load repetitions. The third set was subjected to moisture damage as per the procedure by AASHTO, (2013), and the tesnsile strength ratio TSR was determined. Specimens were tested in triplicate, and the average value was considered for analysis. Figure 1 presents part of the prepared specimens.

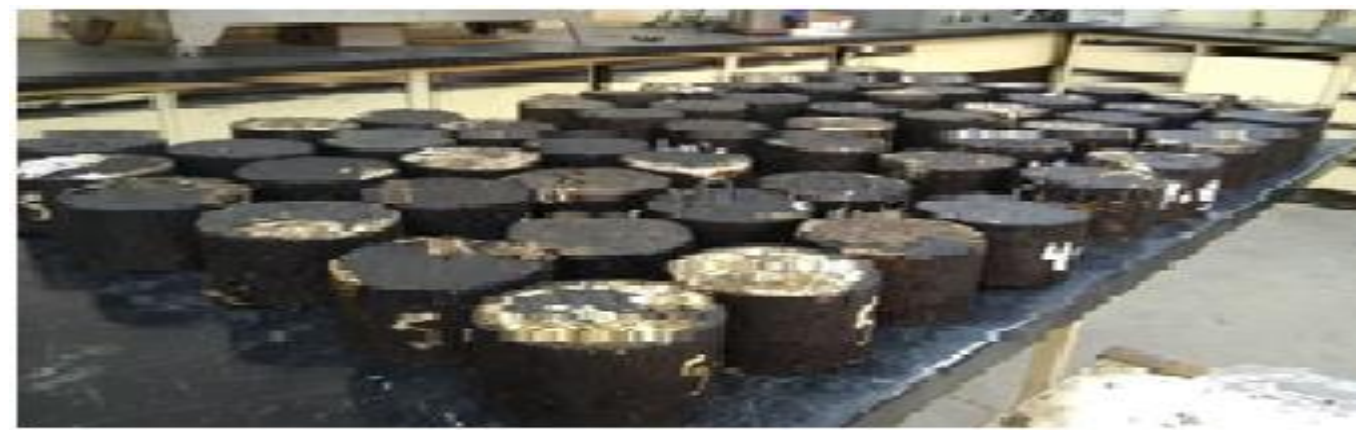

Figure 1. Part of the prepared specimens

\section{d. Moisture Damage Test Process}

This test was performed to assess the resistance to moisture damage of asphalt concrete mixtures; and the procedure of test was conducted according to ASTM D4867, (2013), and AASHTO, (2013). A group of six specimens for each binder and recycling agent content were prepared, three specimens were tested for indirect tensile strength after storage in a water bath at $25^{\circ} \mathrm{C}$ for half an hour; the average strength was considered as (un-conditioned specimens). 
The additional three specimens were conditioned through placing in volumetric flask (4000-ml ) heavy weight- wall glass filled with water at room temperature $25^{\circ} \mathrm{C}$, and a vacuum of 3.74 $\mathrm{kPa}(28 \mathrm{~mm} \mathrm{Hg})$ was applied to the flask for 10 minutes in order to attain $(80 \%)$ level of saturation. The specimens were covered with plastic sheets and stored in deep freezer at ($\left.18^{\circ} \mathrm{C}\right)$ for (16 hours). Then the specimens were placed into a water bath for $(24$ hours) at $\left(60^{\circ} \mathrm{C}\right)$ for thawing. After that, specimens were retained in a water bath on $\left(25^{\circ} \mathrm{C}\right)$ for $(1$ hour $)$. Finally, specimens were tested for indirect tensile strength. The average value was considered as (conditioned specimens). Similar procedure was conducted by Sarsam and Saleem, (2018).

\section{e. Repeated Indirect Tensile Stress Test}

Specimens were subjected to the repeated indirect tensile stresses according to the procedure of ASTM, (2013). In this test, the specimen was stored at room temperature of $25^{\circ} \mathrm{C}$ for one day; then the specimen was transferred to the pneumatic repeated load system PRLS chamber and fixed on the vertical diametrical level between the two parallel loading strips of $(12.7 \mathrm{~mm})$ in width as demonstrated in Figure 2. Asphalt concrete specimens were subjected to repeated indirect tensile stress for 1200 load repetitions at $25^{\circ} \mathrm{C}$. Such timing and test conditions were suggested by Sarsam and Jasim, (2018); Sarsam and Husain, (2017) and Sarsam and AL-Shujairy, (2015). The load assembly applies indirect tensile stress on the specimen in the form of rectangular wave with constant loading frequency of (60) cycles per minutes. A heavier sine pulse of (0.1) sec load duration and (0.9) sec rest period was applied over the test duration. Before the test, dial gage of the deformation reading was set to zero and the pressure actuator was adjusted to the specific stress level of $0.138 \mathrm{MPa}$. A digital video camera was fixed on the top surface of the (PRLS) to capture dial gage reading. The average permanent deformation of duplicate specimens was considered.

\section{f. Repeated Double Punch Shear Test}

This test was implemented to measure the shear strength of asphalt concrete under repeated double punching shear action. Marshall specimens were conditioned in for 30 minutes at $25^{\circ} \mathrm{C}$ before the test. The test starts after fixing the specimen in the PRLS by application of central loading to the cylindrical specimen which is set vertically between the loading platens of the test machine and compressed by two steel punches. The diameter of steel punch is 25.4 $\mathrm{mm}$ located concentrically on the top and bottom surfaces of the cylinder. The load assembly applies axial shear stress on the specimen in the form of rectangular wave with constant loading frequency of (60) cycles per minutes. A heavier sine pulse of (0.1) sec load duration and (0.9) sec rest period was applied over the test duration. Before the test, dial gage of the deformation reading was set to zero and the pressure actuator was adjusted to the specific stress level of $0.138 \mathrm{MPa}$. A digital video camera was fixed on the top surface of the (PRLS) to capture dial gage reading. The average permanent deformation of duplicate specimens was considered. Figure 2. shows repeated Double Punch test setup.
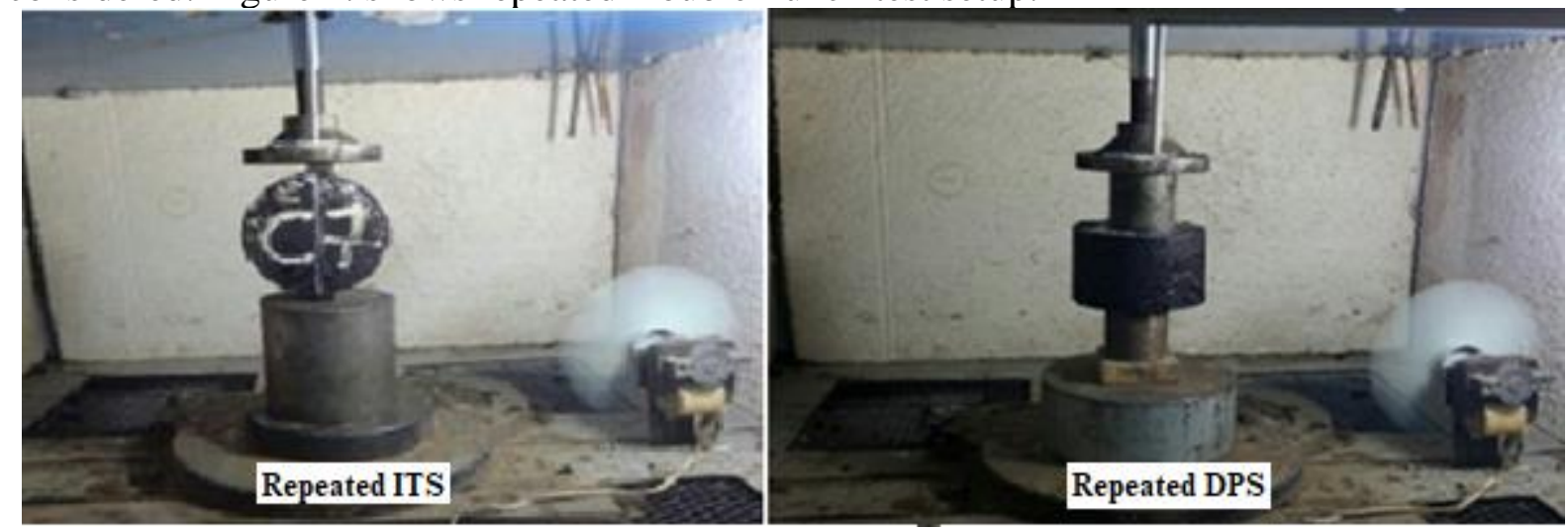

Figure 2 PRLS Chamber for Repeated ITS and DPS testing 


\section{Analysis and Modeling}

\subsection{Modeling the Role of Surface Free Energy on moisture damage of Recycled Asphalt Concrete}

The SPSS software V-25 was utilized for developing the model by adopting different variables which influence the model. Multiple linear regression is utilized when a model is a function of more than one predictor variable. At a chosen confidence level, the obtainable data and the basic assumptions of regression analysis can provide the highest coefficient of determination $\left(\mathrm{R}^{2}\right)$ and lowest mean square error for a given data thus to obtain proper model. A confidence level of 95 percent and significant level of 0.05 were selected. The data should be fissured into two sets; Model building set and Predicted set (qualified as a validation which is used to evaluate the rationality and predicted ability for the selected model. For building the model, $75 \%$ of the original data is used, while $25 \%$ were implemented for validation process, Sarsam and Al-Azawi, (2013).

\subsection{Model Building Process}

To build a model, there are several processes which should be followed, Witczak, and Kaloush, (1999); Samuel, (2019) such as distinguishing the dependent variables, tabulating potential predictors, inquiring in case the necessary conditions are satisfied or not, and use of Statistical software for assessing the model. The choice of the preferable model is based on the statistical output. To build any model, the following condition should be carried out regarding normality of residuals which indicates the distances between the points and the line. Multiple regressions presume that these distances are disseminated in a normal distribution with a mean of zero. Then the homogeneity and independence of residuals at which, the residuals should not be correlated to independent variables and should be normally distributed with egalitarian variance.

\subsection{Identification of the Dependent and Predictor Variables}

To forecast the model, different variables are used; these variables are (SFE) surface free energy $\left(\mathrm{erg} / \mathrm{cm}^{2}\right)$, (DITS) Permanent Deformation under Repeated Indirect Tensile Stress (mm), (DDP) Permanent Deformation under Repeated Double Punching shear stress (mm), and (TSR) tensile strength ratio (\%).

\subsection{Sample size calculations}

Sample size can be computed using the following equation, Sarsam and Al-Sadik, (2014).

$\mathrm{N}=\left(\frac{C V+T}{E}\right)^{2}$

Where:

$\mathrm{N}=$ Sample size,

$\mathrm{E}=$ Error of the mean,

$\mathrm{T}=\mathrm{T}$-statistics,

$\mathrm{CV}=$ Coefficient of variance. 
The sample size was calculated after fissuring $75 \%$ of data to build the model, it can be noted that $(\mathrm{N})$ required is less than the sample size as shown in table, therefore the sample size is accepted.

Table 7. Sample Size Determination

\begin{tabular}{|c|c|c|c|}
\hline Model & Std. dev. & N implemented & N required \\
\hline TSR & 6.93 & 42 & 38 \\
\hline
\end{tabular}

\subsection{Checking for Outliers}

Outlier occurred when one or more of the observation data is obviously diverse from all others. By using Chauvinists' criterion, the outliers and influential observations are checked to inspect the outliers of data used for accuracy Sarsam and Al-Sadik, (2014). Table 8 shows the results of these tests; it can be noted that all tabulated values are higher than the results, therefore there is no outliers.

Table 8. Result of Chauvinists Test of Outliers for SFE Models

\begin{tabular}{|c|c|c|c|c|c|c|c|}
\hline $\begin{array}{c}\text { Dependent } \\
\text { variable }\end{array}$ & $\begin{array}{c}\mathbf{X} \\
\mathbf{m i n}\end{array}$ & $\begin{array}{c}\mathbf{X} \\
\mathbf{m a x}\end{array}$ & $\begin{array}{c}\text { Mean } \\
\left(\mathbf{X}^{\prime}\right)\end{array}$ & $\begin{array}{c}\text { Std. } \\
\text { Deviation( } \\
\mathbf{S})\end{array}$ & $\mid \frac{\mathbf{X} \mathbf{m i n}-\mathbf{X}^{\prime}}{\mathbf{S}}$ & $\mid \frac{\mathbf{X m a x}-\mathbf{X}^{\prime}}{\mathbf{S}}$ & $\mid \frac{\mathbf{X m a x}-\mathbf{X}}{\mathbf{S}}$ \\
\hline $\mathrm{TSR}$ & 3.21 & $\begin{array}{c}21.8 \\
4\end{array}$ & 10.75 & 6.93 & 1.088 & 1.600 & 2.478 \\
\hline
\end{tabular}

\subsection{Normality Test}

Kolmogorov-Smirnov (or K-S test) is used to test if the variables are normally distributed. The K-S statistics (D) are founded upon the extreme distance between F(y) and Fn (y), Sarsam and Al-Sadik, (2014).

$$
\mathrm{D}=\max .[\mathrm{F}(\mathrm{y})-\mathrm{Fn}(\mathrm{y})]
$$

Where

$\mathrm{F}(\mathrm{y})=$ Normal cumulative probabilities (From normal distribution table).

Fn $(y)=$ Sample cumulative distribution function .

$$
D^{+}=\operatorname{Max} \cdot\left[\frac{1}{n}-F(y i)\right]
$$

and, $D^{-}=\operatorname{Max} \cdot\left[F(y i)-\frac{i-1}{n}\right]$

Since: $\mathrm{D}=\operatorname{Max}\left(D^{+}, D^{-}\right)$

Table 9 shows the results of Kolmogorov-Smirnov test for dependent predicted TSR model. Based on these results, the (K-S) computed values are lower than the critical D values, the conclusion for that is the normal distribution of the data. Where (a) indicates that the data distribution is normal; (b) is calculated from data; (c) is the Lilliefors significance correction and (d) is obtained from Kolmogorov Smirnov table. 
Table 9. Kolmogorov-Smirnov Results for TSR Model

\begin{tabular}{|l|c|c|}
\hline \multicolumn{2}{|c|}{ Variable } & TSR \\
\hline Normal Parameter $s^{a, b}$ & Mean & 10.755 \\
\cline { 2 - 3 } & Std. Deviation & 6.93 \\
\hline \multirow{2}{*}{ Most Extreme Differences } & Absolute & 0.208 \\
\cline { 2 - 3 } & Positive & 0.208 \\
\cline { 2 - 3 } & Negative & -0.192 \\
\hline Test Statistic(k-s) D value & 0.208 \\
\hline Critical D value $^{d}$ & 0.220 \\
\hline Asymp. Sig.(2-tailed) & $0.000^{c}$ \\
\hline
\end{tabular}

\subsection{Multicollinearity}

SPSS software version (25) was utilized for identifying the multicollinearity between the independent variables via correlating between them with each other. Confidence level of 95 percent is employed. To find the correlation coefficient for the variables, a correlation matrix is generated and by using SPSS software, the correlation coefficients among all of the variables are computed while the correlation matrix is setup, The decision is based on adding or deleting a variable weather that the variable develops the model or not. The correlation coefficients are determined, and this matrix can be seen in Table 10 for TSR model.

Table 10. Correlations Matrix

\begin{tabular}{|c|c|c|c|c|c|}
\hline \multicolumn{2}{|c|}{ variable } & SFE & DITS & TSR & DDP \\
\hline \multirow{3}{*}{ carson Correlation } & SFE & 1.000 & -0.207 & 0.254 & -0.507 \\
\cline { 2 - 6 } & DITS & -0.207 & 1.000 & 0.708 & 0.171 \\
\cline { 2 - 6 } & TSR & 0.254 & 0.708 & 1.000 & 0.328 \\
\cline { 2 - 6 } & DDP & -0.507 & 0.171 & 0.328 & 1.000 \\
\hline
\end{tabular}

\subsection{Regression Modeling}

Regression modeling is used for determining the relation between two or more numbers of variables to estimate the best model and via using a statistical method. The variable with predicting name (dependent variable) and the variable predicting name (independent or explanatory variable) were implemented in the fundamental equation for multiple regression model (equation 6).

$\mathrm{Y}=A_{\mathrm{a}}+A_{1} X_{1}+A_{2} X_{2}+\ldots+A_{n} X_{n}$

Where:

Y=Predicted depended variable,

$A_{\mathrm{s}}=$ Constant,

$A_{1}=$ Coefficient of $X_{1}$,

$X_{1}=$ Independent variable 1 ,

$n=$ Number of variables

$A_{n}=$ Coefficient of $X_{n}$

$X_{n}=$ Independent variables $\mathrm{n}$. 


\section{a. Stepwise Regression Procedure}

The procedure has been done by computing the simple regression model for every independent variable. The lowest p-value, in different meaning, the independent variable with the highest F-statistic is elected as the first entering variable. SPSS software version 25 uses the F-statistics and the standard is commonly set at $\mathrm{F}=3.84$, because the significant level is about $5 \%$. The standard is named the F-to-enter. The procedure continues, if at least one variable exceeds the standard. It then considers whether the model would be developed by adding a second independent variable. To find out the best model, all models are tested and whether the F-statistic of the second variable (with the first variable previously in the equation) is higher than F-to-enter. If more than one independent variable is strongly correlated, once the first variable is included, from different point of view, only one of them will enter the equation, because F-statistic of this variable will not be great enough to enter the model. The procedure continues by computing ( $p$-values) for all variables at each step and compared to the $\mathrm{F}$ to remove, thus, deciding whether to add another independent variable or not. If a variable Fstatistic decreases below this standard, it is ejected from the equations, Sarsam and Al-Azawi, (2013). The results of ANOVA and summary of stepwise regression, for different possible models can be explained in Table 11 .

Table 11. ANOVA Result for the Model

\begin{tabular}{|l|c|c|c|c|c|c|}
\hline \multicolumn{7}{|c|}{ ANOVA } \\
\hline \multicolumn{2}{|c|}{ Model } & Sum of Squares & df & Mean Square & F & Sig. \\
\hline \multirow{4}{*}{1} & Regression & 506.191 & 1 & 506.191 & 13.812 & .001 \\
\cline { 2 - 7 } & Residual & 1465.904 & 40 & 36.648 & & \\
\cline { 2 - 7 } & Total & 1972.095 & 41 & & & \\
\hline \multirow{3}{*}{2} & Regression & 896.207 & 2 & 448.104 & 16.243 & .000 \\
\cline { 2 - 7 } & Residual & 1075.887 & 39 & 27.587 & & \\
\cline { 2 - 7 } & Total & 1972.095 & 41 & & & \\
\hline 3 & Regression & 1626.027 & 3 & 542.009 & 59.515 & .000 \\
\cline { 2 - 7 } & Residual & 346.067 & 38 & 9.107 & & \\
\cline { 2 - 7 } & Total & 1972.095 & 41 & & & \\
\hline
\end{tabular}

For the model and from table, it can be observed that the value of F statistic (for third option) was greater than value of $\mathrm{F}$ standard (3.84) that leads to ( $\mathrm{p}$ - value) less than 0.05 thus all independent variables enter in the equation of this model. Based on Table 12, it can be noted that the standardized coefficients for(DDP) $(B=-0.720, \mathrm{p}<0.05)$ is significant, the standardized coefficients for (DITS) $(\beta=-0.865, p<0.05)$ is significant, and the standardized coefficients for (TSR) $(\beta=1.103, p<0.05)$ is significant, this explained that the three independent variables are factors to SFE model (model2).

Table 12. Coefficients of Regression Analysis for the Model

\begin{tabular}{|c|c|c|c|c|c|c|}
\hline \multicolumn{7}{|c|}{ Coefficients $^{\text {a }}$} \\
\hline \multicolumn{2}{|c|}{ Model } & \multicolumn{2}{|c|}{ Unstandardized Coefficients } & \multirow{2}{*}{$\begin{array}{c}\begin{array}{c}\text { Standardized } \\
\text { Coefficients }\end{array} \\
\text { Beta }\end{array}$} & \multirow[t]{2}{*}{$\mathrm{t}$} & \multirow[t]{2}{*}{ Sig. } \\
\hline & & B & Std. Error & & & \\
\hline \multirow[t]{2}{*}{1} & (Constant) & 18.125 & 2.192 & & 8.269 & .000 \\
\hline & DDP & -354.306 & 95.333 & -.507 & -3.717 & .001 \\
\hline \multirow[t]{3}{*}{2} & (Constant) & -60.151 & 20.905 & & -2.877 & .006 \\
\hline & DDP & -462.317 & 87.559 & -.661 & -5.280 & .000 \\
\hline & TSR & .994 & .264 & .471 & 3.760 & .001 \\
\hline 3 & (Constant) & -150.412 & 15.682 & & -9.591 & .000 \\
\hline
\end{tabular}


emails: birex.journal@gmail.com

\begin{tabular}{|l|l|r|c|r|r|r|}
\hline DDP & -503.786 & 50.521 & -.720 & -9.972 & .000 \\
\hline & TSR & 2.329 & .213 & 1.103 & 10.94 & .000 \\
& & & & 2 & \\
\hline & DITS & -568.900 & 63.550 & -.865 & -8.952 & .000 \\
\hline
\end{tabular}

\section{b. Models Limitation}

Table 13 described the limitation of the data used to build the model. The objective of the limitation is not to propose that the modeling effort has not been successful. It simply serves to alert of the limitations of the data.

Tables 13. Results of Limitation Data Used for SFE Model 2

\begin{tabular}{|c|c|c|c|}
\hline Variable & DITS & DDP & TSR \\
\hline Minimum & 0.01122 & 0.01010 & 73 \\
\hline Maximum & 0.05118 & 0.04000 & 84.7 \\
\hline Mean & 0.02996 & 0.02079 & 81 \\
\hline
\end{tabular}

\section{c. Goodness of Fit}

For measuring Goodness of fit, there are two measures: Coefficient of determination $\left(R^{2}\right)$, and Standard error of regression (SER). Table 14 illustrates the results of $\left(R^{2}\right.$ and SEE) for TSR model.

Table 14. Correlation Coefficient and Standard Error for the Model

\begin{tabular}{|l|l|l|l|}
\hline Model & R Square & Adjusted R Square & SEE \\
\hline TSR & 0.825 & 0.811 & 3.017 \\
\hline
\end{tabular}

\section{d. Validity of Development Model}

Validation demonstrate how much the models can clarify the engineering or physical phenomena; it is the significant portion for building the model and the objective of validation to evaluate the error and the accuracy of prediction model and for evaluating the capability of prediction model for validation period. The following method was proposed for model validation which includes new data collection, checking the model coefficients and the predictions, make comparisons within previous models, fissuring data and Prediction sum of squares. From the essential sample, the appropriating sample is selected without substitute by using simple random sampling process which considers (75) \% of the original sample and the (25) $\%$ of the original sample is used as validation sample.

\section{e. Diagnostic (Q-Q) Plots}

The relation between the estimated and observed values for (SFE) models can be sketched by (Q-Q) plots and which is a good technique for evaluating the performance of regression equation by using (25) \% of the data which is fissuring from the basic data, Figure 3 show the graphical (Q-Q) plots for the model . 


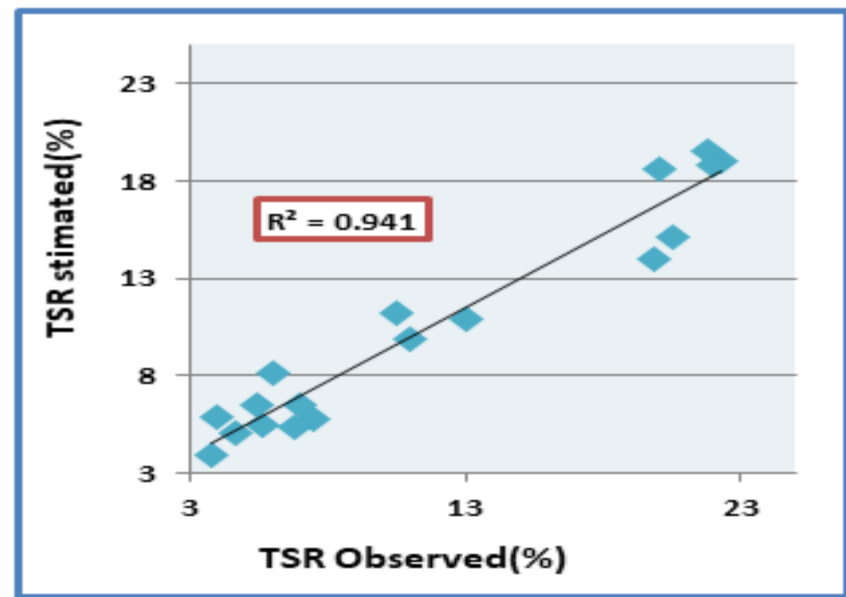

Figure 3. Correlation between Observed and Estimated Values for TSR

\section{f. Residual Analysis}

The variation between an observed value (yi) and the predicted value (yi') as explained by $\left(e i=y i-y i^{\prime}\right)$, which is named a residual (ei). And by subtracts the mean value of residuals (zero) from each residual and dividing by the estimated standard deviation, standardizing residuals can be founded thus for validation of regression model. The following requirements including the probability distribution of the residuals should be satisfied for the validation of regression model regarding the mean of error distribution is zero, and the probability of error distribution is normal, Sarsam and Al-Azawi, (2013). Table 15 shows the relation between standardized residual versus standardized predicted value for modified model and the properties of standardized residuals.

Table 15. Residuals Statistic Properties of TSR Model

\begin{tabular}{|r|r|r|r|r|r|}
\hline \multicolumn{7}{|c|}{ Residuals Statistics } \\
\hline & Minimum & Maximum & \multicolumn{1}{c|}{ Mean } & Std. Deviation & $\mathrm{N}$ \\
\hline Predicted Value & .76113 & 22.7701 & 10.755 & 6.297 & 42 \\
\hline Residual & -7.131 & 4.30548 & -.000 & 2.905 & 42 \\
\hline Std. Predicted Value & -1.587 & 1.908 & .000 & 1.000 & 42 \\
\hline Std. Residual & -2.363 & 1.427 & .000 & .963 & 42 \\
\hline
\end{tabular}

Figure 4 show the histograms of the model and the corresponding $\mathrm{P}-\mathrm{P}$ plots. The distribution has normal looking: it is satisfactorily symmetrical and doesn't appear pointy or flat -with small deviation it is a good result, therefore the distribution of residuals are normally distributed, the P-P plot noticed that the data points all located very close to the 'ideal' diagonal line and tend to be in angle $45^{\circ}$ which consider it a good result for the validation of model. 
emails:birex.journal@gmail.com

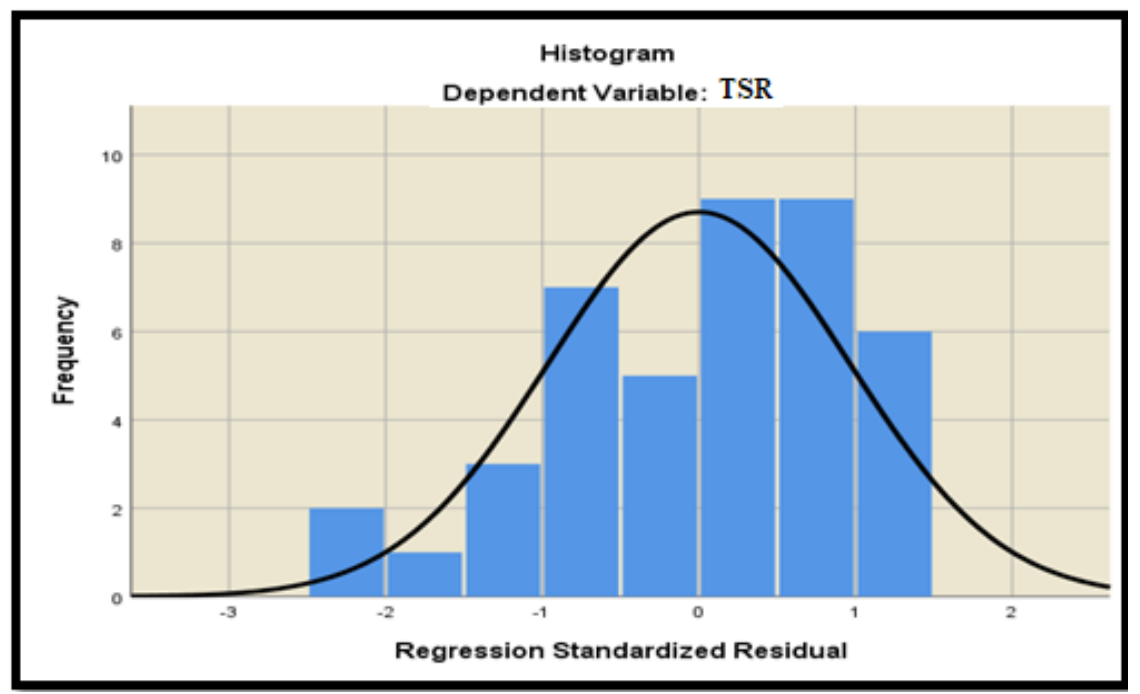

Figure 4. Histograms of the Model and the Corresponding P-P plots

Figure 5 represent the scatter plot for the model, it can be observed that the data point fall near the straight line (zero line) thus a strong correlation between variables of the model. Whilst Figure 6 shows the estimated value of the model. The results of these Table 15 and the Figures showing the error probability distribution is normal with zero mean for the modified model.

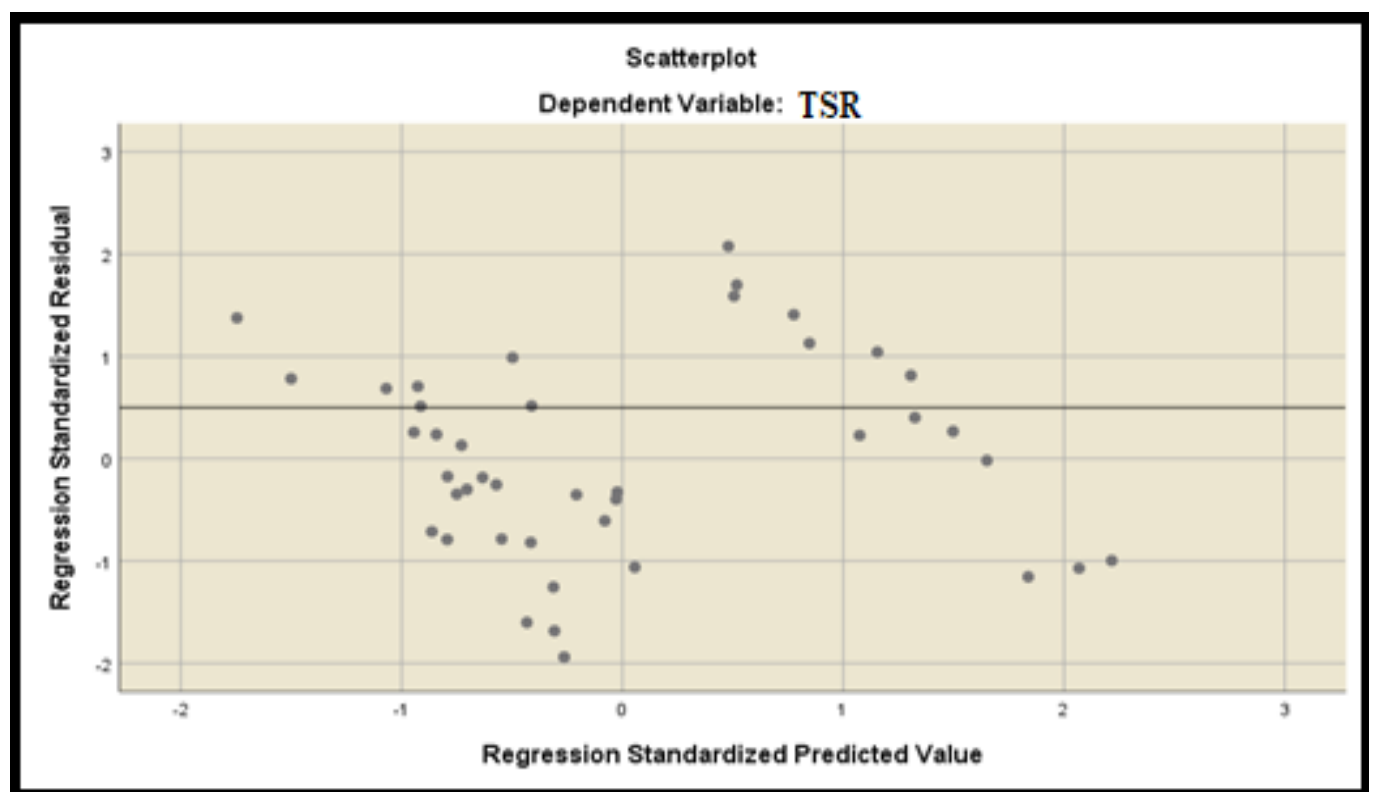

Figure 5. Scatter Plot for TSR 


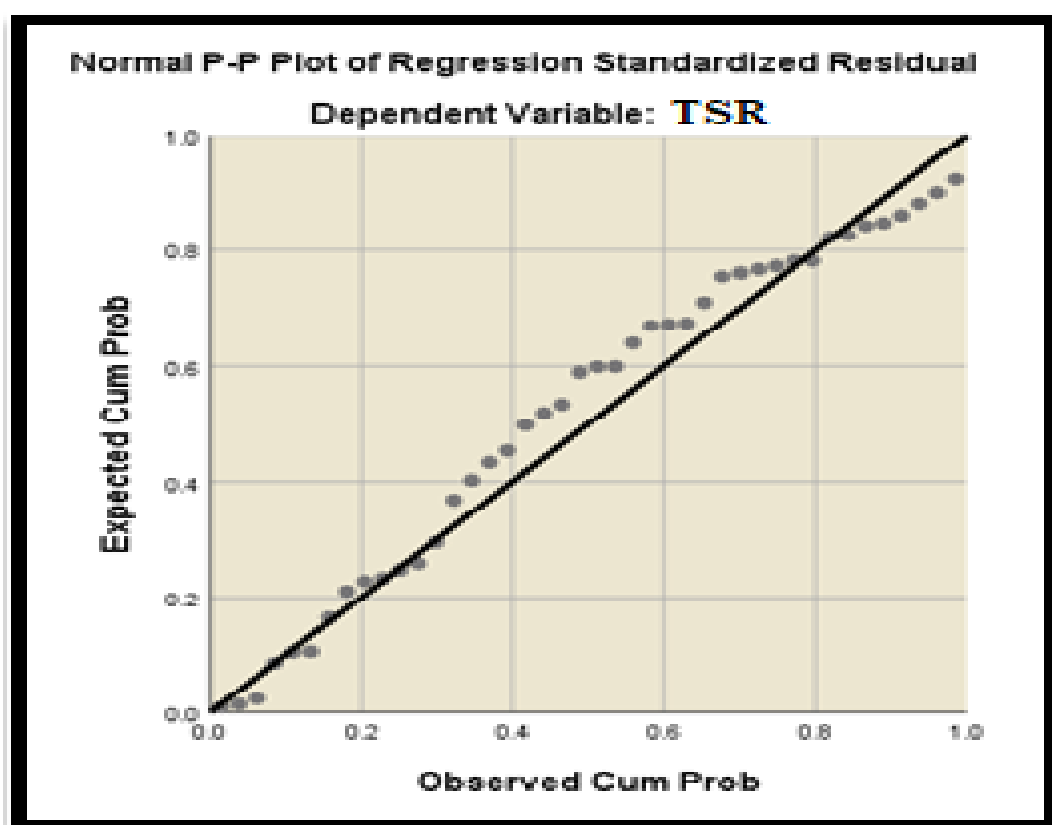

Figure 6. Estimated Value of TSR Models

\section{g. Checking of $\mathbf{R}$-Critical}

$\mathrm{R}$ - value describe the coefficient of correlation between $\mathrm{x}$ and $\mathrm{y}$ and can be considered significant at given probability level when R-tabulated less than R-computed, high (R-Value) does not give a guarantee that the model fits the data well. $\mathrm{R}$ computed $=0.908>\mathrm{R}$ Tabulated $=0.304(\mathrm{n}=42, \mathrm{df}=\mathrm{n}-2=40)$. Therefore, there is sturdy correlation between independent variables and predicted variables in these models.

\section{h. Analysis of Results}

The analysis of results and the computations of standard error regression, and coefficient of determination for surface free energy (SFE) models are shown in Table 16.

Table 16. Correlation Coefficients and Standard Error of Estimation for SFE Models

\begin{tabular}{|c|l|l|l|}
\hline Regression model & $\mathbf{R}^{\mathbf{2}}$ & Adj. $^{\mathbf{2}}$ & SER \\
\hline $\mathrm{SR}(\%)=64.58+216.31$ DDP+244.26 DITS + 0.429 SFE & $\$ 25$ & $\$ 11$ & 77 \\
\hline
\end{tabular}

Where:

TSR $\%=$ Tensile strength ratio

DDP $=$ Permanent Deformation under Repeated Double Punching Test (mm)

DITS $=$ Permanent Deformation under Repeated Indirect Tensile Strength Test (mm)

$\mathrm{SFE}=$ Surface free energy $\left(\mathrm{erg} / \mathrm{cm}^{2}\right)$

The coefficient of determination for tensile strength ratio is found to be $(0.825)$ with a standard error of (.027). From these results obtained, it seems that there is good correlation between observed and estimated values for the model.

\section{Conclusions}

Based on the analysis of test results and limitations of materials, the following conclusions can be drawn.

a. The developed statistical model of resistance to moisture damage is based on permanent deformation under repeated tensile and shear stresses and surface free energy of the 
binder.

b. 2- The model can explain $82.5 \%$ of the variations in tensile strength ratio with reasonable standard error of estimate of (0.027).

c. 3- The model can be utilized for asphalt concrete mixtures within the limitations of materials regardless of the modifiers used and recycling process adopted.

\section{References}

Matic B. J., Salem A. H., Radonjanin V. S., Radovic. M., Sermac. R. (2016). Modeling the surface stored thermal energy in asphalt concrete pavements. Thermal Science Volume $\begin{array}{llll}\text { 20, Issue } & \text { suppl. } & 2, & \text { Pages: }\end{array}$ https://doi.org/10.2298/TSCI150930042M.

Iskakbayev A., Teltayev B., Rossi C. (2017). Modeling of Cyclic Strength for the Asphalt Concrete Considering Damage Accumulation. Appl. Sci., 7, 1270; doi:10.3390/app7121270.

Zhou J. and Chen X. (2019). Modeling the Linear Viscoelastic Behavior of Asphalt Concrete via Optimization Method. Proceedings, CICTP: Transportation in China-Connecting the World (916 - 927).

Panoskaltsis V. and Dinesh Panneerselvam D. (2007). Theoretical Aspects in Modeling Asphalt Concrete and Pavements. Symposium on Pavement Mechanics and Materials. Pavements and Materials: Characterization, Modeling, and Simulation (1 - 15).

Sarsam S. I. and Al-Azawi I. (2013). Modeling the Stripping Potential of Asphalt Concrete. Proceedings, Airfield and Highway Pavement: Sustainable and Efficient Pavements ASCE 2013. P. 999-1007.

Ramanujam, J.M., (2000). Recycling of Asphalt Pavements, Department of Transport \& Main roads, Queensland, Available online: http://www.docstoc.com/docs/42047013/recycling of asphalt-pavements. (18/07/2018).

Perez F., Rodriguez M., De Visscher J., Vanelstraete A., De Bock L., (2004). Design and Performance of Hot Mix Asphalts with High Percentages of Reclaimed AsphaltApproach Followed in the PARAMIX Project, Proceedings of the 3rd Euroasphalt \& Eurobitume Congress, Vienna, paper-098.

Nurmaidah and Pradana Y. (2019). The Effect of the Mixture of Plastic Waste as a Lightweight Concrete Material. Budapest International Research in Exact Sciences (BirEx) Journal. Volume 1, No 2, April, Page: 65-75. DOI : https://doi.org/10.33258/birex.v1i2.227.

Silva H., Oliveira J., Jesus C. (2012). Are totally recycled hot mix asphalts a sustainable alternative for road paving? Resources, Conservation and Recycling 60 P. 38- 48. Doi: 10.1016/j.resconrec.2011.11.013.

Kim S., Jeong J., Kim N. (2003). Use of surface free energy properties to predict moisture damage potential of Asphalt concrete mixture in cyclic loading condition, KSCE Journal of Civil Engineering, Volume 7, Issue 4, July, P. 381-387.

Pradyumna T., and Jain P. (2014). Use of RAP Stabilized by Hot Mix Recycling Agents in Bituminous Road Construction. Transportation Research Procedia, 11th Transportation Planning and Implementation Methodologies for Developing Countries, TPMDC 2014, 10-12 December, Mumbai, India Volume 17, 2016, P. 460-467 DOI: 10.1016/j.trpro.2016.11.090.

Sarsam S. I., and Hamdan R. K. (2019). Influence of Recycling Agent on Surface Free Energy of Asphalt Cement. American Journal of Traffic and Transportation Engineering. Vol. 4, No. 1, P. 17-23. Doi: 10.11648/j.ajtte.20190401.13.

Sarsam S. I. (2007). A study of aging and recycling of Asphalt Concrete pavement. University of Sharjah, Journal of pure and applied Sciences, Vol.4 No.2 June P.79-94 Sharjah UAE. 
Sarsam S. and Abdulhussain M. (2018). Assessing Surface Free Energy Component of Modified Asphalt Cement. Proceedings, 4th Conference of the Middle East Society of Asphalt Technologists, MESAT 2018, July 4-6, Beirut- Lebanon pp. 65-75.

ASTM, (2013). Road and Paving Materials. Annual Book of ASTM Standards, Volume 04.03, American Society for Testing and Materials, USA.

SCRB (2003). Standard Specification for Roads and Bridges. Section R/9, Revised Edition. State Commission of Roads and Bridges, Ministry of Housing and Construction, Republic of Iraq.

Little D. and Bhasin A. (2006). Using Surface Energy Measurements to Select Materials for Asphalt Pavement. NCHRP Web only document 104, Final Report for NCHRP Project 9-37. National Cooperative Highway Research Program. USA.

AASHTO. (2013). Standard Specification for Transportation Materials and Methods of Sampling and Testing, American Association of State Highway and Transportation Officials, 14th Edition, Part II, Washington, D.C.

Sarsam S. I. and Jasim S. A. (2018). Assessing the Impact of Polymer Additives on Deformation and Crack Healing of Asphalt Concrete Subjected to Repeated Compressive Stress. Proceedings, 17th Annual International Conference on: Asphalt, Pavement Engineering and Infrastructure, 2018 LJMU, Wednesday 21st and Thursday 22nd February, Liverpool, UK.

Sarsam S. I. and Husain H. K. (2017). Influence of Healing Cycles and Asphalt Content on Resilient Modulus of Asphalt Concrete. Trends in Transport Engineering and Applications. STM Journals, Vol.4 No.1 p. 23-30.

Sarsam S. I. and AL-Shujairy A. M. (2015). Assessing Tensile and Shear Properties of Recycled Sustainable Asphalt Pavement. Journal of Engineering, June, Volume 21, No.6.

Sarsam S. I., Al-Sadik S. M. (2014). Modeling Aging Impact on Physical Properties of Asphalt Cement. Research Journal of Modeling and Simulation, RJMS, May, Vol. 1(2) (P20-29). Sciknow Publications Ltd. USA.

Witczak, M. W., \& Kaloush, K. (1999). Development of Permanent to Elastic Strain Ratio Model for Asphalt Mixtures, Development of the 2002 Guide for the Design of New and Rehabilitated Pavement Structure, University of Maryland, College Park, Maryland.

Samuel A. F. (2019) On the Performance of Transmuted Logistic Distribution: Statistical Properties and Application. Budapest International Research in Exact Sciences (BirEx) Journal. Volume 1, No 3, July, Page: 26-34.

DOI: https://doi.org/10.33258/birex.v1i3.341. 